\title{
A New Building for the Oldest Spinal Cord Unit in The Netherlands
}

\author{
F.W.A. van Asbeck, MD, PhD \\ Rehabilitation Centre 'De Hoogstraat', Rembrandtkade 10, 3583 TM Utrecht, The \\ Netherlands.
}

\section{History}

In June 1953 the first spinal cord injury unit in The Netherlands was established in a mansion called 'De Hoogstraat', which had belonged to the pre-war Prime Minister, Colijn. This mansion stood isolated in the woods near Leersum, a small village in the centre of the country. During the 35 years that followed, this single unit was further developed into a 146-bed rehabilitation centre with a 34-bed SCI Unit, a stroke unit, an amputation unit, a children's department, a self care unit and an outpatient rehabilitation department.

The isolation of this complex proved to be a handicap, not only for the fast growing outpatient department but also for the reintegration of the inpatients into society.

When a major renovation of the whole centre was due, it was decided that a new centre should be built on the outskirts of the provincial capital Utrecht 25 kilometres away.

On 26 May 1988 the centre was transferred to its new building and the official opening by H.R.H. Princess Margriet took place on 1 November 1988.

\section{Philosophy}

The rehabilitation centres in The Netherlands have no facilities for acute care, so all centres have a co-operative arrangement with a nearby general hospital. Since 'De Hoogstraat' has a formal working relationship with the University Hospital in Utrecht, the SCI patients of the region are first admitted to that hospital and are then transferred to the centre when the vital functions are stabilised. This usually takes between 1 and 2 weeks. SCI patients from other regions are admitted through other general hospitals after the same period.

In the rehabilitation centre each department is headed by a 'revalidatie-arts', who is a medical doctor specialising in rehabilitation medicine. This specialty requires a post-graduate training of 4 years including all major fields of rehabilitation medicine. In the departments of the centre the 'revalidatie-arts' attends to the medical problems of the patients, sets objectives for the paramedical, nursing and psychosocial staff and co-ordinates the activities of the consultants. 


\section{Rehabilitation in The Netherlands}

The Netherlands cover an area of 300 by $200 \mathrm{~km}$ of which the western third lies below sea-level. The country has an excellent infrastructure of roads, railways and communication systems.

The population is just over 14000000 of which 600000 are first or second generation immigrants mainly from the Mediterranean and the West Indies.

Although more than half of the population lives in the western third of the country, 4 of the 6 SCI units are established in the eastern part of the country (Fig. 1). Thus 'De Hoogstraat' SCI unit caters for the central and south-western part of the Netherlands. A seventh unit is planned for Rotterdam and will probably be opened by the mid-1990s.

\section{Physical facilities}

The new centre is located in a residential area of the city near a park with shops and pubs around the corner (Fig. 2).

The SCI unit has 16 beds for tetraplegic and 18 for paraplegic patients. The number of admissions is around 80 per year.

In the unit are 6 rooms with 4 beds and 5 rooms with 2 beds (Fig. 3, Fig. 4). These rooms are located along 2 dead end corridors which prevents a lot of internal traffic noise.

The departments for occupational therapy, physiotherapy (Fig. 5), hydrotherapy, sport and the swimming pool (Fig. 6) are shared with the other departments of the rehabilitation centre. The same applies for the psychosocial departments and the wheelchair, orthopaedic and adaptation workshops.

An X-ray room also with ultrasound facilities, and a basic laboratory are available. More complicated investigations, including urodynamic studies, are performed in the university hospital.

\section{Staffing}

The medical staff of the SCI unit consists of one 'revalidatie-arts' and a resident medical officer, who does part of his/her post-graduate training there. Visiting specialists from the university hospital attend on a regular basis, and include an orthopaedic surgeon, physician, urologist, neurologist and a plastic surgeon.

The nursing staff consists of about 45 registered and enrolled nurses making up 34 full-time positions.

The paramedical staff consists of 3 full-time and 1 part-time physiotherapists and 2 full-time and 1 part-time occupational therapists.

The psychosocial staff consists of 1 full-time and 1 part-time social worker and 1 part-time psychologist.

\section{Training}

All professional groups working in the SCI unit have a training agreement with a school in their particular field and medical, nursing and paramedical trainees do part of their training in this department. 


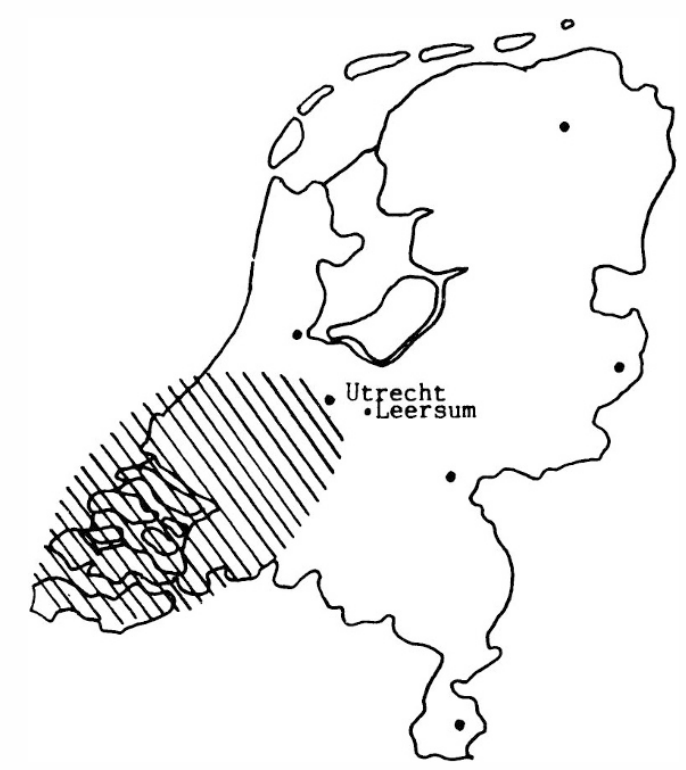

Figure 1 Map of the Netherlands with the 6 SCI units and the working area of the SCI unit in the 'De Hoogstraat' rehabilitation centre, Utrecht.

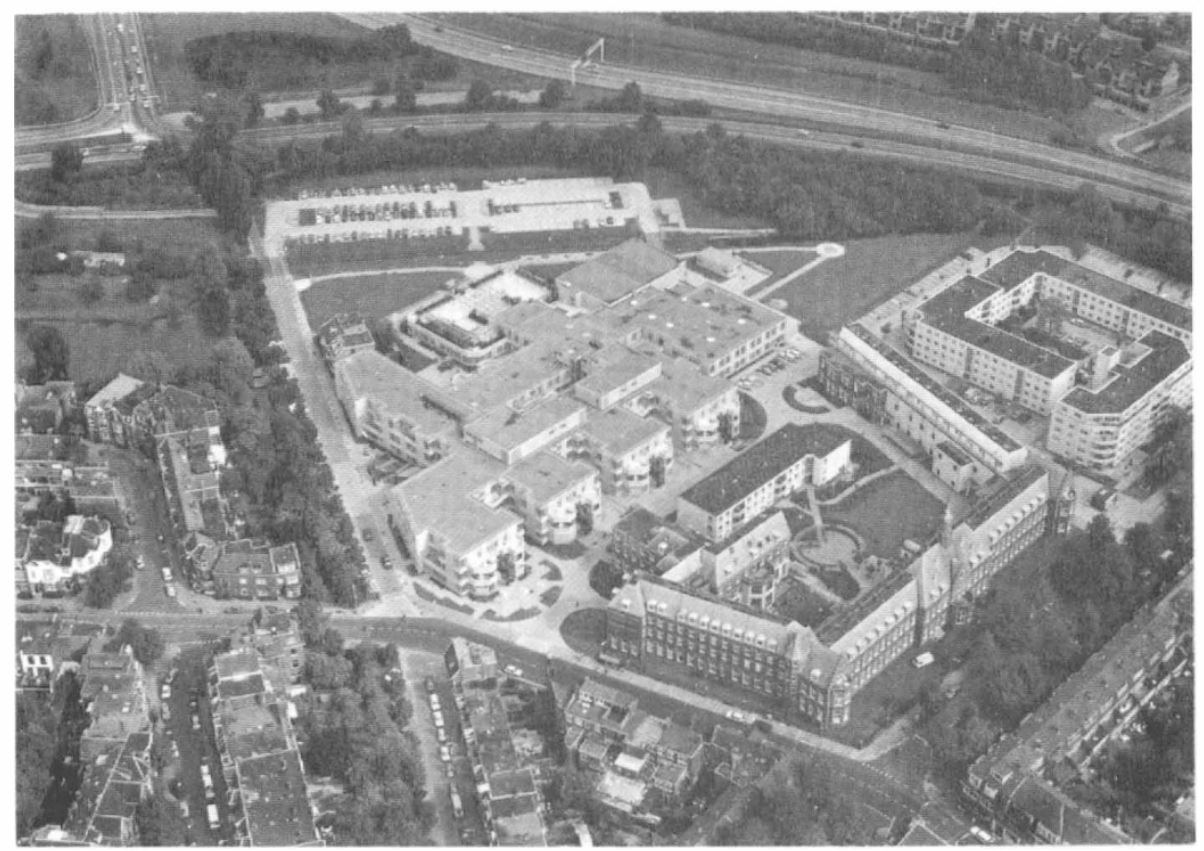

Figure 2 Aerial view of the new centre. 


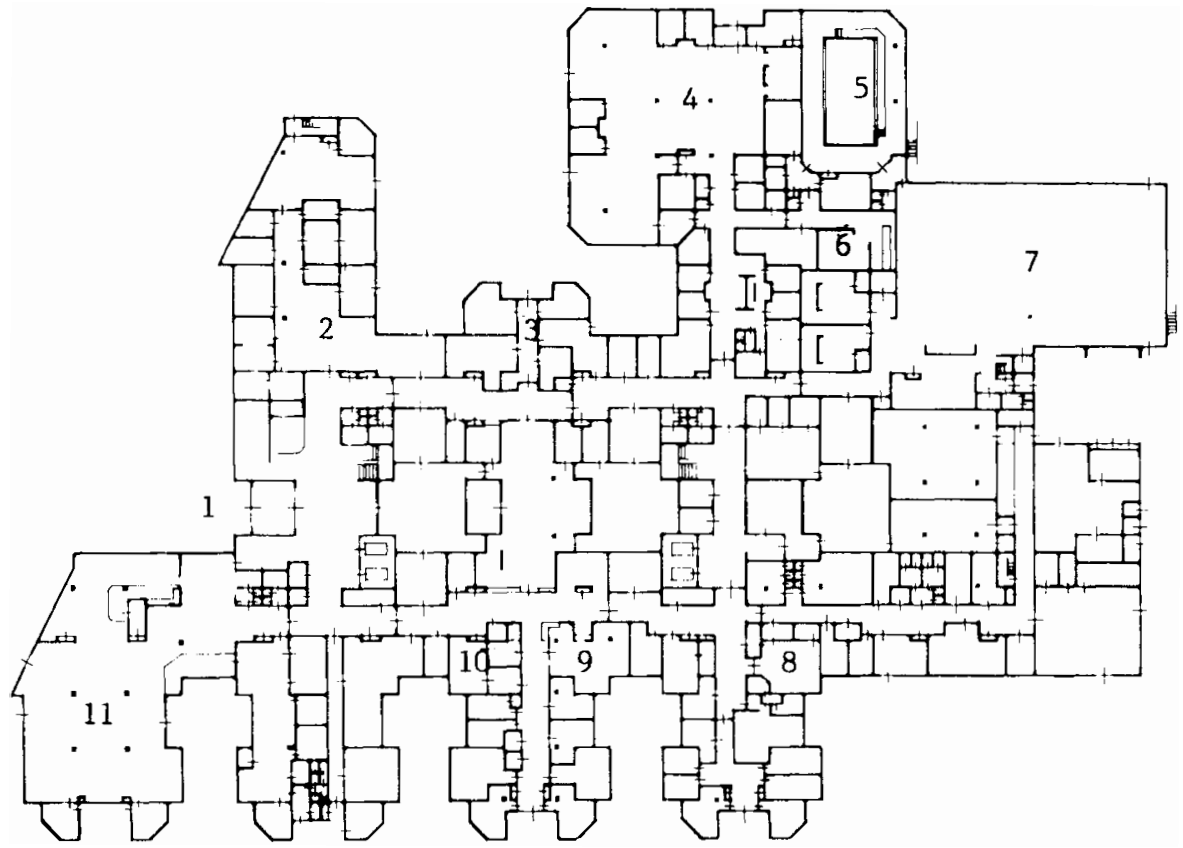

Figure 3 Plan of the ground floor. 1: Entrance, 2: Occupational therapy, 3: Speech therapy, 4: Physiotherapy, 5: Swimming pool, 6: Hydrotherapy, 7: Sports hall, 8: X-ray department, 9: Clinics, 10: Laboratory, 11: Restaurant.

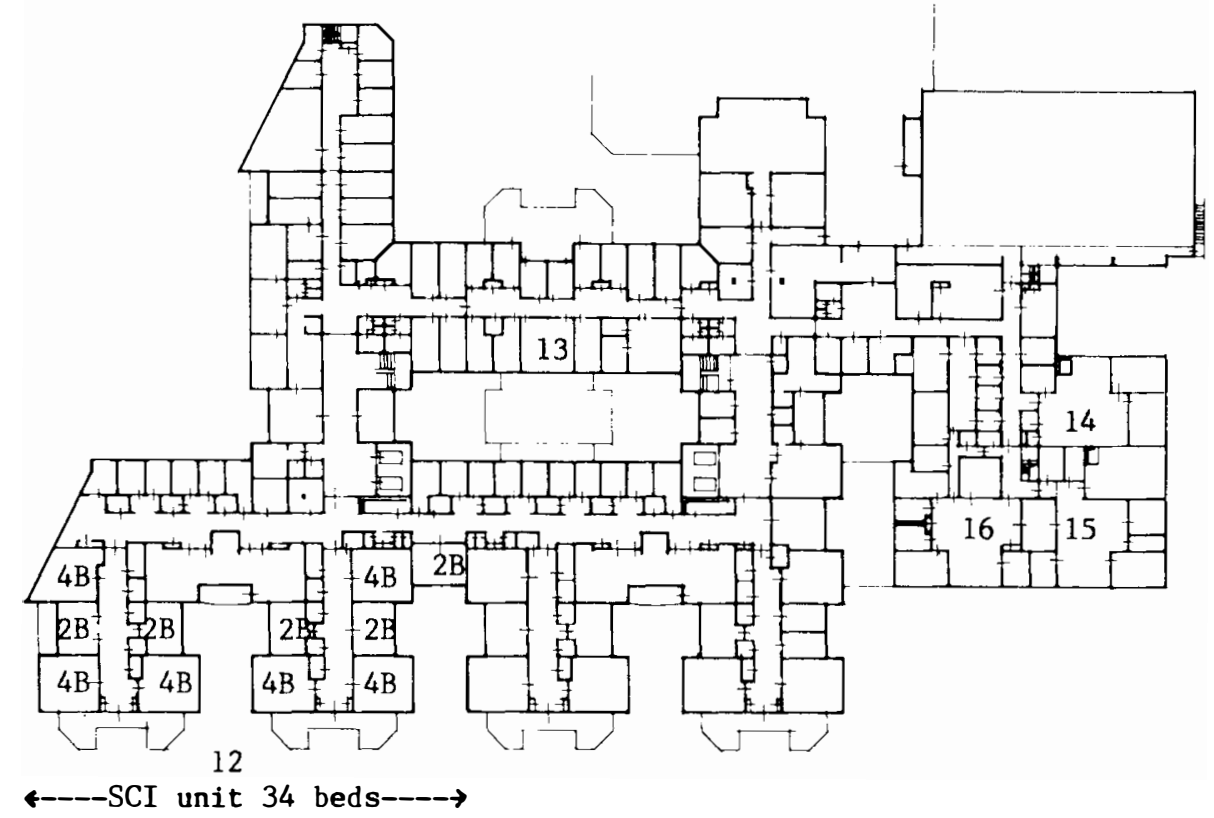

Figure 4 Plan of the first floor. 12: SCI unit, 13: Psychosocial department, 14: Wheelchair workshop, 15: Adaptation workshop, 16: Orthopaedic workshop. 


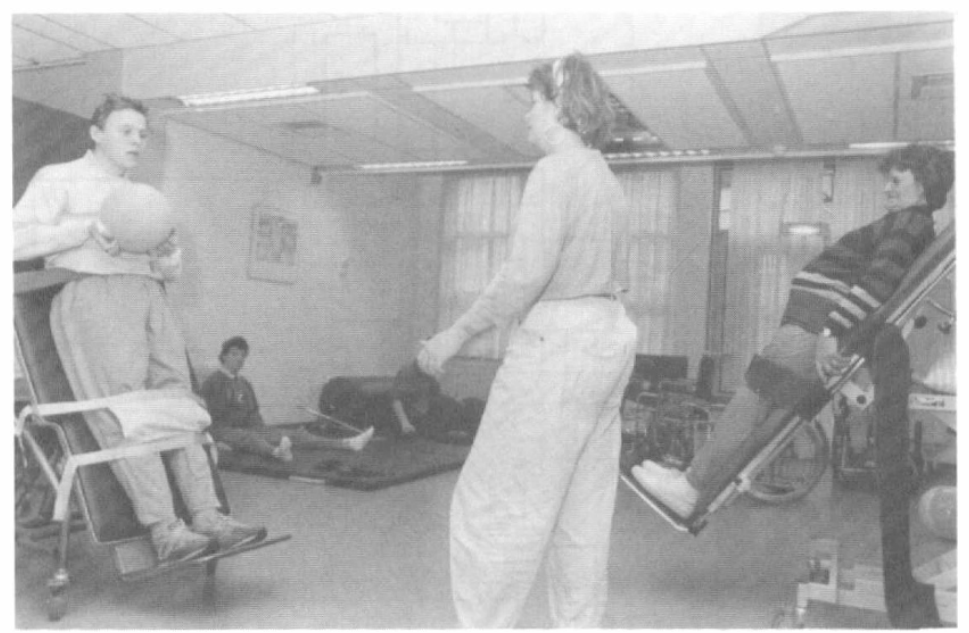

Figure 5 Physiotherapy department.

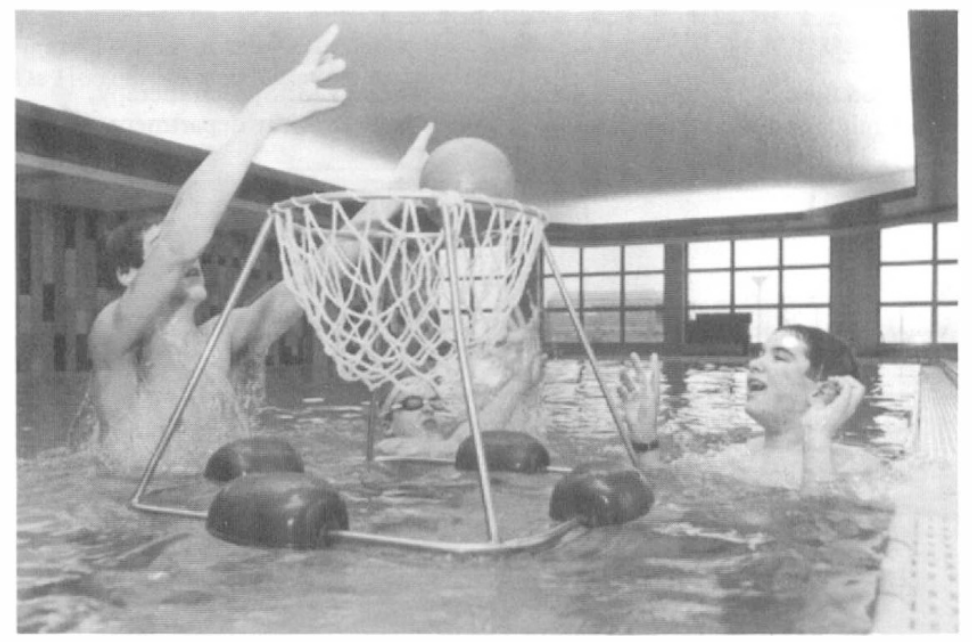

Figure 6 Swimming pool.

\section{Research}

So far research in this department has been in the sphere of evaluation studies of the rehabilitation process. After the transfer to Utrecht and co-operation with the Medical Faculty of the Utrecht University is established, we hope to embark on more research projects in the near future.

\section{Conclusion}

With this new centre we hope to give a proper service to our patients and to keep up with developments in this field in the future. 